\title{
Klotho Gene and Selective Serotonin Reuptake Inhibitors: Response to Treatment in Late-Life Major Depressive Disorder
}

\author{
Giulia Paroni ${ }^{1}$ (D) - Davide Seripa ${ }^{1} \cdot$ Andrea Fontana $^{2} \cdot$ Grazia D'Onofrio $^{1} \cdot$ \\ Carolina Gravina $^{1}$ - Maria Urbano ${ }^{1} \cdot$ Filomena Addante $^{1} \cdot$ Madia Lozupone $^{3}$. \\ Massimiliano Copetti ${ }^{2}$ - Alberto Pilotto ${ }^{4}$ - Antonio Greco ${ }^{1}$ - Francesco Panza ${ }^{1,3}$
}

Received: 20 May 2015 / Accepted: 11 January 2016

(C) Springer Science+Business Media New York 2016

\begin{abstract}
Klotho protein, encoded by the Klotho gene (KL) at locus $13 \mathrm{q} 12$, is an antiaging hormone-like protein playing a pivotal role in cell metabolism homeostasis and associated to longevity and age-related diseases. In particular, altered cell metabolism in central nervous system may influence the behavior of serotoninergic neurons. The role of KL in the response to treatment with selective serotonin reuptake inhibitors (SSRIs) in late-life depressive syndromes and late-life major depressive disorder (MDD) is unclear. We genotyped three single-nucleotide polymorphisms (SNPs) of KL in 329 older patients with diagnosis of late-life MDD, treated with SSRIs and evaluated with the Hamilton Rating Scale for Depression 21-items (HRSD-21) at baseline and after 6 months. A reduction $\geq 50$ and $<10 \%$ in HDRS- 21 score was considered as response or nonresponse to therapy, respectively, and the values of reduction between 10 and $49 \%$ as poor responders. After 6 months of SSRI treatment, 176
\end{abstract}

Electronic supplementary material The online version of this article (doi:10.1007/s12035-016-9711-y) contains supplementary material, which is available to authorized users.

Giulia Paroni

giulia.paroni@operapadrepio.it

1 Gerontology-Geriatric Research Laboratory, Department of Medical Sciences, I.R.C.C.S. "Casa Sollievo della Sofferenza", 71013 San Giovanni Rotondo, Foggia, Italy

2 Biostatistic Unit, I.R.C.C.S. "Casa Sollievo della Sofferenza”, 71013 San Giovanni Rotondo, Foggia, Italy

3 Neurodegenerative Disease Unit, Department of Basic Medicine, Neuroscience, and Sense Organs, University of Bari Aldo Moro, Bari, Italy

4 Geriatrics Unit, Department of OrthoGeriatrics, Rehabilitation and Stabilitation, Frailty Area, Galliera Hospital NR-HS, Genoa, Italy patients responded, 54 patients did not respond and 99 patients showed a poor response. Ordinal logistic models showed a significant association between mutation of SNP rs1207568 and responders and, similarly, for each unitary risk allele increase overlapping results were found. Conversely, a significantly higher frequency of the minor genotype of SNP rs9536314 was found in nonresponders. Considering the pre-post differences of HRSD-21 scores as a continue variable, we confirmed a significant improvement of depressive symptoms after treatment in patients carrying at least one minor allele at rs1207568 and a worse response in patients homozygous for the minor allele at rs9536314. Our results were the first that suggested a possible role of $\mathrm{KL}$ in the complex pathway of SSRI response in late-life MDD.

Keywords Klotho $\cdot$ Late-life depression · Late-life major depressive disorder · Selective serotonin reuptake inhibitors . Response to treatment . Older age

\section{Introduction}

Among neuropsychiatric disorders, depression is increasingly becoming common and disabling in older age [1]. Late-life depression (LLD) refers to depressive syndromes that arise in adults older than 65 years [2, 3], encompassing both late-onset as well as early-onset cases that recur or continue into later years of life [4]. Prevalence estimates of clinically significant LLD vary widely from 4.5 to $37.4 \%$ according to the population studied, sample size, and nonpsychiatric comorbidity [5]. Furthermore, in LLD, there is a general consensus on a syndromal approach to depression to identify symptom clusters such as major depressive disorder (MDD) [2, 3]. Among late-life depressive syndromes, clinically significant MDD is a common disease in Western countries with a pooled 
prevalence of $7.2 \%[5]$ and an incidence rate of $0.2-14.1 / 100$ person-years [6]. It has been also recently reported that LLD may result in increased risks of comorbidity [7], polypharmacy [8], frailty [9], and also all-cause mortality [10], thus becoming a major public health concern for the next future $[1,11,12]$. Despite these data, LLD is still under recognized in clinical practice, with less than $10 \%$ of older subjects that have formal evaluation and treatment for this condition [11-13].

According to a recent hypothesis, MDD may be the result of a dysregulation of the stress system in response to a predisposing, stressful environment $[14,15]$. Stress in life is unavoidable, affecting everyone on a daily basis. Psychological stress in mammals triggers a rapidly organized response for survival, but it may also cause a variety of behavioral disorders and depression [16]. The same hypothesis strongly links MDD to parainflammation and endoplasmatic reticulum (ER) stress and to three potential interrelated modulators of this process, the central nervous system (CNS) insulin, the peroxisome proliferator-activated receptor- $\gamma$, and Klotho. Parainflammation is an adaptive response of the innate immune system that occurs in the context of stressors to which we were not exposed during our early evolution, including overfeeding, underactivity, aging, and drugs [17, 18]. Multiple physiological or pathological conditions that affect protein folding or overload the capacity of ER to fold proteins, i.e., increased glutamate stimulation [18] or overfeeding [19], can cause ER stress, an imbalance between the cellular demand for ER function and ER capacity [20]. If the ER response is overwhelmed, substantial amounts of calcium are released into the cytoplasm, leading to apoptosis [18]. Therefore, ER stress is involved in disease states because it can lead to cell death or compromise of cellular resilience [21, 22]. The stress response also plays important roles in numerous human pathophysiological processes caused by protein misfolding and retention in the ER, organismal responses to malignancy, neurodegeneration, atherosclerosis, and type 2 diabetes [17, 18, 21-24]. Moreover, a failed ER stress response may play an important role in the depressive syndrome, in part by leading to cell loss or decreased cellular resiliency [20].

Klotho, originally identified as an antiaging protein in mice [25], plays a major role in the biochemical pathways regulating ER stress response. Klotho protein ameliorates chemically induced ER stress signaling [26], and Klotho gene (KL) may be a potential translational target in ER stress in MDD. Klotho-deficient mice showed an increased overall burden of CNS oxidative stress [27], suggesting that this protein may exert brain-wide antioxidative and anti-inflammatory effects $[28,29]$. Klotho decreases parainflammation and improves the efficiency of the ER stress response induced by an upregulation of KL that may be relevant in increasing neuronal resilience in MDD patients [14, 15, 20], including adaptive hippocampal neurogenesis, thus suggesting that KL functional genetic variations may alter MDD resilience and treatment. Currently, selective serotonin reuptake inhibitors (SSRIs) are the first-line pharmacological treatment of moderate and severe depression in older adults [30]. Several clinical trials, however, reported a variable response rate to SSRI up to $65 \%$, particularly in older patients [31,32]. While major evidences suggested an important contribution of pharmacogenetics in SSRI response in younger subjects, the role of genetics in SSRI response in LLD is still under debate [33-36]. The aim of the present study was to investigate the $\mathrm{KL}$ gene polymorphisms to evaluate a potential involvement of this gene in the response to SSRI treatment in patients with late-life MDD.

\section{Methods}

\section{Subjects}

The present study was conducted fulfilling the Declaration of Helsinki, the guidelines for Good Clinical Practice and the Strengthening the Reporting of Observational Studies in Epidemiology (STROBE) guidelines [37]. From January 2009 to May 2011, a total of 1311 older subjects who consecutively attended the Geriatric Unit of the Istituto di Ricovero e Cura a Carattere Scientifico (IRCCS) Casa Sollievo della Sofferenza and who self-reported depressive symptoms were screened for possible study enrollment (Fig. 1). The approval of the study for experiments using human subjects was obtained from the local Ethics Committee on human experimentation. Written informed consent for research was obtained from each patient or from relatives/legal guardian in the case of critically disabled demented patients. All the 329 older subjects enrolled were Caucasians and did not include people of Jewish, Eastern Europe, or Northern Africa descent, with most individuals having Central and Southern Italy ancestry.

\section{Inclusion/Exclusion Criteria}

Inclusion criteria were as follows: (1) Caucasian race; (2) age $\geq 65$ years; (3) diagnosis of MDD according to the criteria of the Diagnostic and Statistical Manual of Mental Disorders, Fourth Edition, Text Revision (DSM-IV-TR) [2]; (4) need for the treatment with antidepressants of the SSRI class; (5) Mini Mental State Examination (MMSE) [38] score $\geq 15$, because of the use of the 15-item Geriatric Depression Scale (GDS-15) $[39,40]$ that has been validated within this MMSE score limit [41]; and (6) written informed consent. Patients were excluded from the study if (1) they had age at onset of depression before 65 years, (2) they refuse to enter in the study or to sign the informed consent, (3) they were already in treatment with SSRIs or other antidepressants, or had 
a recent history (last year) of therapy with antidepressants or other psychotropic drugs (benzodiazepines, antipsychotics, mood stabilizers), (4) a severity of MDD not allowing to collect adequate data, and (5) a MMSE score $<15$.

\section{Study Protocol}

At baseline, demographic and clinical characteristics were collected by a structured interview and clinical evaluation. All included patients with late-life MDD were initially treated for 2 weeks with escitalopram $5 \mathrm{mg} /$ daily, sertraline $25 \mathrm{mg} /$ daily, paroxetine $10 \mathrm{mg} /$ daily, or citalopram $10 \mathrm{mg}$ /daily on the basis of the clinical judgment of the physician, who was unaware of the genetic profile of the patient. Two weeks after that dose titration was completed, 41 patients dropped out because of adverse drug reactions (ADRs) $(n=8)$ or because of refusal to undergo the follow-up treatment $(n=33)$ (Fig. 1). Patients who had followed the treatment with satisfactory or good compliance and without clinically relevant ADRs $(n=329)$ increased the dosage of escitalopram to $10 \mathrm{mg} /$ daily, sertraline to $50 \mathrm{mg} /$ daily, paroxetine to $20 \mathrm{mg}$ /daily, or citalopram to $20 \mathrm{mg}$ /daily for the following 22 weeks (Fig. 1). After treatment, the clinical assessment was repeated, including the evaluation of cognitive and functional status, compliance, and drug-related adverse events.

\section{Diagnosis of Depression and Response to Treatment}

Diagnosis of late-life MDD was made according to the diagnostic criteria from the DSM-IV-TR [2] using the GDS-15 to evaluate depressive symptoms. To define the response to treatment with SSRIs, we used the Hamilton Rating Scale for Depression with 21 items (HRSD-21) [42] that evaluates the depressive symptoms. Initially, as previously reported [42, 43], we defined as responder (R) a patient who showed a reduction of at least $50 \%$ on the HRSD-21 score, as poorresponder (PR) if the reduction was between 10 and $49 \%$, and as nonresponder (NR) if the reduction is $<10 \%$ [10]. Afterward, we considered the HRSD-21 as a continue variable to compare the variations between baseline and follow-up.

\section{Genetic Analysis}

Genomic DNA was purified from fresh/frozen blood samples following salting-out method [44]. In the present study, we analyzed the three single-nucleotide polymorphisms (SNPs) rs1207568, rs9536314, and rs564481. The SNPs were chosen for their functional role in altering protein product (rs1207568) [45] or amino acid (rs9536314 and rs564481) [46]. Overall, these SNPs span $45 \mathrm{~kb}$ block at the KL locus (13p12) $(33,590,184-33,634,983$ bases from pter). The SNP rs1207568 (33,590,184 bases from pter), i.e., the $\mathrm{C}^{4,614} \rightarrow \mathrm{T}$ near the 5 'UTR of the KL gene, was determined with the allele discrimination assay using TaqMan technology. Briefly, genomic DNA was analyzed with the ABI PRISM 7700 Sequence Detector system (Life Technologies Corporation, Carlsbad, CA, USA) using the assay c 760479210 according to manufacturer instructions. The SNP rs9536314 (33,628,138 bases from pter), i.e., the $G^{42 \text {, }}$ $568 \rightarrow \mathrm{T}$ in exon 2 of the KL gene causing the amino acid change $\mathrm{Phe}^{352} \rightarrow$ Val, was determined as follows. Briefly, genomic DNA was amplified by PCR with a hot-start at $94{ }^{\circ} \mathrm{C}$ for $7^{\prime}$, followed by 30 cycles at $94^{\circ} \mathrm{C}$ for $30^{\prime \prime}, 50^{\circ} \mathrm{C}$ for $30^{\prime \prime}$, and $72{ }^{\circ} \mathrm{C}$ for $30^{\prime \prime}$. The PCR product ( $279 \mathrm{bp}$ ) was digested with Mae III for $6 \mathrm{~h}$ at $55^{\circ} \mathrm{C}$. The analysis on a $3 \%$ agarose gel electrophoresis revealed the three genotypes T/T $(232+$ $47 \mathrm{bps}), \mathrm{T} / \mathrm{G}(232+182+50+47 \mathrm{bps})$, and $\mathrm{G} / \mathrm{G}(182+50+$ $47 \mathrm{bps})$. The SNP rs564481 (33,634,983 bases from pter), i.e., the $\mathrm{C}^{49,413} \rightarrow \mathrm{T}$ causing the sense amino acid change $\mathrm{His}^{589} \rightarrow$ His in exon 4 of the KL gene was determined with the allele discrimination assay using TaqMan technology. Briefly, genomic DNA was analyzed with the ABI PRISM 7700 Sequence Detector system (Life Technologies Corporation, Carlsbad, CA, USA) using the assay c_592739_10 according to manufacturer instructions. No differences were observed in respect to the expected HardyWeinberg equilibrium for one locus. No differences were also observed when the present genotype frequencies were compared with those reported form the 1000 genomes project (http://www.1000genomes.org). We also analyzed at the solute carrier family 6 (neurotransmitter transporter, serotonin), member 4 (SLC6A4) locus the polymorphism C, also known as 5HTT gene linked polymorphic region (5HTTLPR) and cytochrome P450 (CYP) 2D6 as previously described $[47,48]$ to avoid the possibility that these two factors may influence our analysis.

\section{Statistical Analysis}

Patients' baseline characteristics were reported as mean \pm standard deviation or frequencies and percentage for continuous and categorical variables, respectively. Normal distribution assumptions were checked by means of Q-Q plot and Shapiro-Wilks and Kolmogorov-Smirnov tests. Comparisons between continuous variables were performed using twosample $t$ test or Mann-Whitney $U$ test, in case of nonnormal distributed data. Comparisons between categorical variables were performed using Pearson chi-squared test or Fisher exact test, as appropriate. Associations between KL genotypes and the patient response to SSRI treatment were assessed using both multivariable ordinal logistic regression models (which assumes that the coefficients that describe the relationship between R or PR vs. NR is the same as those that describe the relationship between $\mathrm{R}$ vs. PR or NR), and multivariable ANOVA models (which modeled the pre-post reduction of HRSD-21 scores) for categorical and continuous SSRI 
treatment response, respectively. Multivariable ordinal logistic models were adjusted for age, sex, educational level, SSRI treatment type, and 5-HTTLPR genotype, assuming different genetic models of inheritance (i.e., dominant, recessive, and additive) $[49,50]$. Multivariable ANOVA models were adjusted for HRSD-21 score at baseline, age, sex, educational level, SSRI treatment type, and 5-HTTLPR genotype, assuming different genetic models of inheritance (i.e., dominant, recessive, and additive). Risks were reported as odds ratio (OR) along with their $95 \%$ confidence interval $(95 \% \mathrm{CI})$. The greater the HRSD-21 mean reduction, the better the treatment response. Adjusted means of HRSD-21 reduction, along with standard errors, were eventually estimated for each KL genotype, within each SNP, separately. To control for multiple comparisons, $p$ values derived from both multivariable models were further adjusted following Hochberg's method $(\operatorname{adj} p)$. For sake of completeness, binary logistic regression multivariable models were further estimated within $\mathrm{R}$ vs. NR, PR vs. NR, and R vs. PR groups, separately. The HaploView 4.2 genetic software package was used to estimate the values of linkage disequilibrium (LD) coefficient $r^{2}$ as well as to estimate and compare haplotype frequencies at the KL locus, between the study groups [51]. $p$ Values $<0.05$ were considered for statistical significance. All statistical analyses were performed using SAS, version 9.3 (SAS Institute, Cary, NC).

\section{Power Calculation}

To detect a statistical association between any KL genotype (e.g., major/major vs. minor/major vs. minor/minor) and treatment response (i.e., R vs. PR vs. NR), a sample size of 329 patients achieves $80 \%$ power to detect a Cohen's effect size (W) [52] of 0.19 using a Pearson's chi-squared test evaluated on a two-way contingency table with $(3-1) \times(3-1)=4^{\circ}$ of freedom, with a significance level of 0.05 .

\section{Results}

\section{Demographic and Clinical Characteristics of Patients}

The analysis was carried out on 329 patients with late-life MDD (95 men and 234 women, mean age $77.58 \pm 6.63$ years, age range from 65 to 94 years) (Fig. 1). Demographic and clinical characteristics of patients at baseline are summarized in Table 1. No significant differences were observed between men and women in age, MMSE score, and SSRI treatments. Conversely, a significant difference between genders was observed in educational level $(p<0.001)$, in the GDS-15 score $(p=0.007)$, and in the HRSD-21 scores $(p=0.002)$. Baseline and follow-up clinical characteristic of patients according to the status of response to SSRI treatment are summarized in
Fig. 1 Flowchart of patients with late-life major depressive disorder (MDD) screened for possible study enrollment. $C D R$ Clinical Dementia Rating, MMSE Mini Mental State Examination, GDS-15 15-item Geriatric Depression Scale, HRSD-21 Hamilton Rating Scale for Depression 21 items, $M D D$ major depressive disorder, $A D R$ adverse drug reaction, $\triangle H R S D-21$ pre-post differences of HRSD-21 scores from baseline to the end of treatment with selective serotonin reuptake inhibitors

Table 2. No significant differences were observed between R, PR, and NR patients with late-life MDD in gender distribution, age, educational level, HRSD-21, GDS-15, and MMSE scores at baseline. Moreover, no significant differences were observed in response distribution (R vs. PR vs. NR) in patients treated with the four different SSRIs. As expected, at followup, significant differences were observed in the HRSD-21 score and in GDS-15 score among the three groups of patients (R vs. PR vs. NR). Moreover, MMSE score at follow-up was significantly higher in $\mathrm{R}$ than $\mathrm{PR}(p=0.017)$ and NR groups $(p=0.002)$.

\section{Genotype Analyses}

Genotype distribution at KL locus according to the status of response to SSRI treatment is summarized in Table 3. There was a significant difference of genotype distribution among all of the three groups for the SNP rs9536314 $(\operatorname{adj} p=0.033)$. The associations between KL genotypes and the status of response to SSRI treatment are summarized in Table 4. We found that rs1207568 followed a dominant and an additive model of inheritance, whereas rs9536314 followed a recessive model of inheritance. Indeed, results from ordinal logistic models showed that patients who carried at least one minor allele at rs1207568 had a significantly better response to SSRI treatment than those who carried both major alleles $(\mathrm{OR}=2.29$, $95 \%$ CI 1.35-3.87, adj $p=0.006)$ and, similarly, for each unitary risk allele increase $(\mathrm{OR}=2.13,95 \%$ CI 1.33-3.40, adj $p=0.005$ ), overlapping results were found. Conversely, patients who were homozygous for the mutation at rs9536314 had a significantly worse response to SSRIs treatment than those who carried at least one major allele $(\mathrm{OR}=0.14,95 \%$ CI 0.03-0.63, adj $p=0.031)$.

Looking at the pre-post differences in HRSD-21 scores (HRSD-21 reduction) as a continuous variable, the analysis evidenced that patients carrying at least one minor allele at rs1207568 achieved higher improved response to treatment, independently of their baseline HRSD-21 and SSRIs treatment type than patients carrying major alleles (adj $p=0.021)$. Indeed, a mean reduction of $10.46(95 \% \mathrm{CI}$ 9.11-11.81) and 8.69 (95\% CI 7.59-9.79) points of HRSD21 were estimated in both groups, respectively. Conversely, patients homozygous for the minor allele at rs9536314 showed a worse response to SSRI treatment (adj $p=0.026)$. Indeed, a mean reduction of 4.11 (95\% CI 0.15-8.07) and 
Jan 2009 - Dec 2011

1311 consecutive patients screen ed for LLD

467 males and 844 fem ales

Age $\geq 65$ years

$\downarrow$

Excluded $(\mathrm{n}=602)$ :

- Age at onset of depression before 65 years $(n=345)$

- Refusal to sign the informed consent $(n=52)$

- Diagnosis of dem entia $(\mathrm{CDR}=1 / \mathrm{MMSE}<15)(\mathrm{n}=205)$

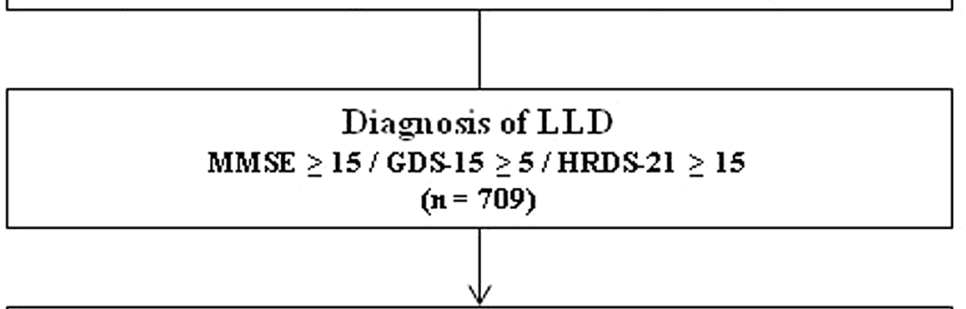

Excluded $(n=339)$ :

- Minor depressive disorder $(n=244)$

- Dysthimic disorder $(n=59)$

- Adjustment disorder with depressive $\operatorname{mood}(n=33)$

- Bipolar I disorder with the most recent episode depressed $(n=3)$

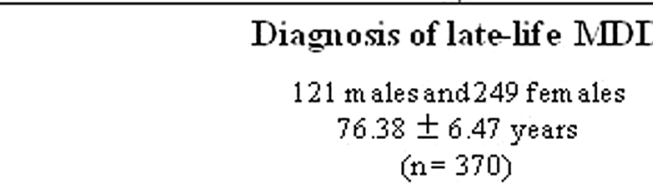

(Escitalopram $5 \mathrm{~m}$ g/daily, sertraline $25 \mathrm{~m}$ g/daily, parox etine $10 \mathrm{~m}$ g/daily, citalopram $10 \mathrm{~m}$ g/daily for 2 weeks)

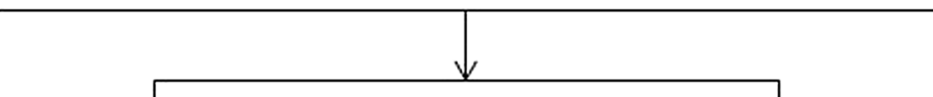

Excluded $(\mathrm{n}=41)$ :

- Drop-out for $A D R(n=8)$

- Refusal to underwent the follow-up $(\mathrm{n}=33)$

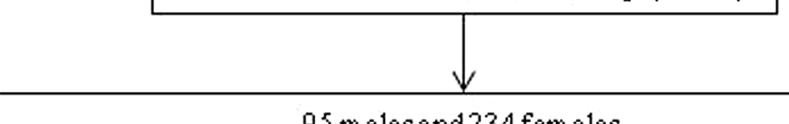

$95 \mathrm{~m}$ ales and 234 fem ales

$77.58 \pm 6.63$ years

$(n=329)$

(Escitalopram $10 \mathrm{~m}$ g/daily, sertraline $50 \mathrm{~m}$ g/daily, parox etine $20 \mathrm{~m}$ g'daily, citalopram $20 \mathrm{~m}$ g/daily for the next $22 \mathrm{weeks})$

\begin{tabular}{|c|c|c|}
\hline$\sqrt{v}$ & $v$ & $\nabla$ \\
\hline $\begin{array}{c}\text { Responders } \\
\text { (Delta-HDRS-21 } \geq 50 \% \text { ) }\end{array}$ & $\begin{array}{c}\text { Poor-responders } \\
\text { (Delta-HDRs-21 } \quad 10-49 \% \text { ) }\end{array}$ & $\begin{array}{c}\text { Non-responders } \\
\text { (Delta-HDRS-21 }<10 \% \text { ) }\end{array}$ \\
\hline $\begin{array}{c}53 \text { males and } 123 \text { females } \\
78.283 \pm 6.87 \text { years } \\
(\mathrm{n}=176)\end{array}$ & $\begin{array}{c}33 \text { malesand } 66 \text { females } \\
76.86 \pm 6.14 \text { years } \\
(\mathrm{n}=99)\end{array}$ & $\begin{array}{c}9 \text { males and } 45 \text { females } \\
75.59 \pm 6.57 \text { years } \\
(\mathrm{n}=54)\end{array}$ \\
\hline
\end{tabular}


Table 1 Demographic and baseline clinical characteristic of patients with late-life major depressive disorder according to gender

\begin{tabular}{|c|c|c|c|c|}
\hline & All & Men & Women & $p^{*}$ \\
\hline \multicolumn{5}{|l|}{ Age (years) } \\
\hline Mean $\pm \mathrm{SD}$ & $77.58 \pm 6.63$ & $78.34 \pm 6.30$ & $77.27 \pm 6.75$ & $0.186^{* *}$ \\
\hline \multicolumn{5}{|c|}{ Educational level (years) } \\
\hline Mean \pm SD & $4.05 \pm 3.32$ & $5.07 \pm 3.85$ & $3.63 \pm 2.98$ & $<0.001$ \\
\hline \multicolumn{5}{|l|}{ HRSD-21 } \\
\hline Mean \pm SD & $19.74 \pm 5.55$ & $18.18 \pm 5.96$ & $20.37 \pm 5.26$ & 0.002 \\
\hline \multicolumn{5}{|l|}{ GDS-15 } \\
\hline Mean \pm SD & $9.23 \pm 2.56$ & $8.63 \pm 2.57$ & $9.46 \pm 2.53$ & 0.007 \\
\hline \multicolumn{5}{|l|}{ MMSE } \\
\hline Mean $\pm \mathrm{SD}$ & $21.50 \pm 4.67$ & $22.19 \pm 4.37$ & $21.22 \pm 4.77$ & 0.093 \\
\hline \multicolumn{5}{|l|}{ SSRIs n (\%) } \\
\hline Citalopram & $12(3.65 \%)$ & $2(2.11 \%)$ & $10(4.27 \%)$ & 0.112 \\
\hline Escitalopram & $200(60.79 \%)$ & $67(70.53 \%)$ & $133(56.84 \%)$ & \\
\hline Paroxetine & $25(7.60 \%)$ & $7(7.37 \%)$ & $18(7.69 \%)$ & \\
\hline Sertraline & $92(27.96 \%)$ & $19(20.00 \%)$ & $73(31.20 \%)$ & \\
\hline
\end{tabular}

HRSD-21 Hamilton Rating Scale for Depression 21 items, GDS-15 Geriatric Depression Scale 15 items, MMSE Mini Mental State Examination, SD standard deviation, SSRIs selective serotonin reuptake inhibitors

${ }^{a} p$ Values from Mann-Whitney $U$ and chi-squared tests for continuous and categorical variables, respectively; ** $p$ value from two-sample $t$ test
9.28 (95\% CI 8.26-10.30) points of HRSD-21 were estimated in patients carrying both minor alleles at rs9536314 with respect to those who carrying at least one of major alleles, respectively. No statistically significant associations between the SLC6A4 5HTTLPR or CYP2D6 SNPs and treatment response were found (data not shown).

Table 2 Baseline and follow-up clinical characteristic of patients with late-life major depressive disorder according to the response to the treatment with selective serotonin reuptake inhibitors (SSRIs)

\begin{tabular}{|c|c|c|c|c|c|c|c|}
\hline & & Responders (R) & $\begin{array}{l}\text { Poor-responders } \\
(\mathrm{PR})\end{array}$ & $\begin{array}{l}\text { Nonresponders } \\
\text { (NR) }\end{array}$ & R vs. PR $p^{*}$ & R vs. NR $p^{*}$ & PR vs. NR $p^{*}$ \\
\hline $\begin{array}{l}\text { Percentage of the total } \\
\text { sample }\end{array}$ & $n(\%)$ & $176(53.5 \%)$ & $99(30.09 \%)$ & $54(16.41 \%)$ & & & \\
\hline Gender & Males/females (M\%) & $53 / 123(30.11 \%)$ & $33 / 66(33.33 \%)$ & $9 / 45(16.67 \%)$ & 0.580 & 0.051 & 0.027 \\
\hline Age (years) & Mean \pm SD & $78.28 \pm 6.87$ & $76.86 \pm 6.14$ & $76.59 \pm 6.57$ & $0.088^{* *}$ & $0.112 * *$ & $0.803 * *$ \\
\hline Educational level (years) & Mean \pm SD & $4.33 \pm 3.84$ & $3.69 \pm 2.69$ & $3.77 \pm 2.30$ & 0.696 & 0.799 & 0.591 \\
\hline HRSD-21 cutoff (\%) & & $\geq 50$ & $49-10$ & $<10$ & & & \\
\hline Baseline & Mean \pm SD & $20.09 \pm 4.11$ & $18.85 \pm 7.28$ & $20.24 \pm 5.88$ & 0.875 & 0.241 & 0.647 \\
\hline Follow-up & Mean $\pm \mathrm{SD}$ & $7.97 \pm 1.70$ & $13.48 \pm 6.02$ & $21.02 \pm 5.19$ & $<0.001$ & $<0.001$ & $<0.001$ \\
\hline \multicolumn{8}{|l|}{ GDS-15 } \\
\hline Baseline & Mean \pm SD & $9.16 \pm 1.78$ & $9.22 \pm 3.36$ & $9.43 \pm 2.81$ & 0.651 & 0.687 & 0.554 \\
\hline Follow-up & Mean \pm SD & $5.98 \pm 1.48$ & $6.60 \pm 2.02$ & $9.55 \pm 2.94$ & 0.009 & $<0.001$ & $<0.001$ \\
\hline \multicolumn{8}{|l|}{ MMSE } \\
\hline Baseline & Mean \pm SD & $23.03 \pm 3.90$ & $22.31 \pm 4.20$ & $22.46 \pm 3.96$ & 0.612 & 1.000 & 1.000 \\
\hline Follow-up & Mean \pm SD & $24.39 \pm 3.58$ & $22.91 \pm 4.35$ & $22.19 \pm 4.01$ & 0.017 & 0.002 & 0.935 \\
\hline \multicolumn{8}{|l|}{ SSRIs $n(\%)$} \\
\hline & $\begin{array}{l}\text { Citalopram } \\
\text { Escitalopram }\end{array}$ & $\begin{array}{l}11(6.25 \%) \\
100(56.82 \%)\end{array}$ & $\begin{array}{l}1(1.01 \%) \\
65(6566 \%)\end{array}$ & $\begin{array}{l}0(0 \%) \\
35(6481 \%)\end{array}$ & 0.098 & 0.192 & 0.350 \\
\hline & Paroxetina & $13(7.39 \%)$ & $10(10.1 \%)$ & $2(3.7 \%)$ & & & \\
\hline & Sertraline & $52(29.55 \%)$ & $23(23.23 \%)$ & $17(31.48 \%)$ & & & \\
\hline
\end{tabular}

HRSD-21 Hamilton Rating Scale for Depression 21 items, GDS-15 Geriatric Depression Scale 15 items; MMSE Mini Mental State Examination, SD standard deviation

${ }^{*} p$ Values from Mann-Whitney $U$ and chi-squared tests for continuous and categorical variables, respectively; ${ }^{* *} p$ values from two-sample $t$ test 
Table 3 Genotype distribution at Klotho locus according to the response to the treatment with selective serotonin reuptake inhibitors

\begin{tabular}{llllll}
\hline & Genotype/allele & Responders $(n=176)$ & Poor-responders $(n=99)$ & Nonresponders $(n=54)$ & $p^{*}$ \\
\hline rs1207568 & C/C $(n=230)$ & $112(63.64 \%)$ & $78(78.79 \%)$ & $40(74.07 \%)$ & 0.065 \\
& C/T $(n=90)$ & $57(32.39 \%)$ & $19(19.19 \%)$ & $14(25.93 \%)$ & 0.130 \\
& T/T $(n=9)$ & $7(3.98 \%)$ & $2(2.02 \%)$ & $0(0.00 \%)$ & 0.011 \\
rs9536314 & T/T $(n=226)$ & $117(66.48 \%)$ & $72(72.73 \%)$ & $12(22.22 \%)$ & 0.033 \\
& T/G $(n=95)$ & $58(32.95 \%)$ & $25(25.25 \%)$ & $5(9.26 \%)$ & $0.011 \%)$ \\
rs564481 & G/G $(n=8)$ & $1(0.57 \%)$ & $2(2.02 \%)$ & $28(51.85 \%)$ & 0.438 \\
& C/C $(n=132)$ & $65(36.93 \%)$ & $39(39.39 \%)$ & $19(35.19 \%)$ & 0.438 \\
& C/T $(n=145)$ & $81(46.02 \%)$ & $45(45.45 \%)$ & $7(12.96 \%)$ & \\
\hline
\end{tabular}

${ }^{*} p$ Values from Fisher exact test; ${ }^{* *} p$ values adjusted following Hochberg's method

Results from multivariable logistic regressions, estimated within R vs. NR, PR vs. NR, and R vs. PR groups, separately were further reported in Supplemental Table 1 (appendix online). Moreover, as shown in Supplemental Table 2 (appendix online), 99 late-life MDD patients without $\mathrm{C} / \mathrm{C}$ for $\mathrm{KL}$ rs1207568 and without G/G for KL rs9536314 achieved the highest response to SSRI treatment, with a mean HRSD-21 reduction of 10.37 (95\% CI 9.03-11.71) points. Conversely, eight patients with $\mathrm{G} / \mathrm{G}$ for KL rs 9536314 and without $\mathrm{T} / \mathrm{T}$ for KL rs1207568 achieved the poorest response to antidepressant treatment, with a mean HRSD-21 reduction of 4.16 (95\% CI 0.22-8.08) points. Finally, the remaining 222 patients achieved a medium-high mean HRSD-21 reduction of 8.78 (95\% CI 7.69-9.87).

\section{Haplotype Analysis}

Estimated haplotype frequencies spanning a $4.5-\mathrm{kb}$ block at the klotho (KL) gene locus are summarized in Table 5. In all groups, the most frequent haplotype was $\mathrm{H} 1$, with a frequency

Table 4 Association of Klotho genotypes according to the response to the treatment with selective serotonin reuptake inhibitors (SSRIs) assuming different genetic models of inheritance

\begin{tabular}{|c|c|c|c|c|c|c|c|c|}
\hline & \multirow[b]{2}{*}{ Model } & \multirow[b]{2}{*}{ Genotype/allele } & \multicolumn{3}{|l|}{ HRSD-21 mean reduction ${ }^{\mathrm{a}}$} & \multicolumn{3}{|c|}{ Ordinal logistic regression $^{\mathrm{b}}$} \\
\hline & & & Adjusted means $(95 \% \mathrm{CI})^{\mathrm{b}}$ & Raw $p$ & $\operatorname{Adj} p^{\mathrm{c}}$ & OR $(95 \% \mathrm{CI})$ & Raw $p$ & $\operatorname{Adj} p^{c}$ \\
\hline \multirow[t]{5}{*}{ rs 1207568} & \multirow[t]{2}{*}{ Dominant } & $\mathrm{C} / \mathrm{C}(n=230)$ & $8.69(7.59-9.79)$ & 0.007 & 0.021 & 1.00 (ref.) & - & - \\
\hline & & $\mathrm{C} / \mathrm{T}+\mathrm{T} / \mathrm{T}(n=99)$ & $10.46(9.11-11.81)$ & & & $2.29(1.35-3.87)$ & 0.002 & 0.006 \\
\hline & \multirow[t]{2}{*}{ Recessive } & $\mathrm{C} / \mathrm{C}+\mathrm{C} / \mathrm{T}(n=320)$ & $9.18(8.15-10.22)$ & 0.117 & 0.234 & 1.00 (ref.) & - & - \\
\hline & & $\mathrm{T} / \mathrm{T}(n=9)$ & $11.92(8.41-15.43)$ & & & $3.70(0.75-18.12)$ & 0.107 & 0.213 \\
\hline & Additive & For each risk allele $(\mathrm{T})$ increase & Slope (SE) 1.60 (0.56) & 0.005 & 0.014 & $2.13(1.33-3.40)$ & 0.002 & 0.005 \\
\hline \multirow[t]{5}{*}{ rs9536314 } & \multirow[t]{2}{*}{ Dominant } & $\mathrm{T} / \mathrm{T}(n=226)$ & $9.01(7.92-10.10)$ & 0.188 & 0.188 & 1.00 (ref.) & - & - \\
\hline & & $\mathrm{T} / \mathrm{G}+\mathrm{G} / \mathrm{G}(n=103)$ & $9.86(8.48-11.24)$ & & & $1.28(0.79-2.09)$ & 0.317 & 0.317 \\
\hline & \multirow[t]{2}{*}{ Recessive } & $\mathrm{T} / \mathrm{T}+\mathrm{T} / \mathrm{G}(n=321)$ & $9.28(8.26-10.30)$ & 0.009 & 0.026 & 1.00 (ref.) & - & - \\
\hline & & $\mathrm{G} / \mathrm{G}(n=8)$ & $4.11(0.15-8.07)$ & & & $0.14(0.03-0.63)$ & 0.010 & 0.031 \\
\hline & Additive & For each risk allele $(\mathrm{G})$ increase & Slope (SE) 0.24 (0.58) & 0.679 & 0.679 & $1.03(0.66-1.59)$ & 0.898 & 0.898 \\
\hline \multirow[t]{5}{*}{ rs564481 } & \multirow[t]{2}{*}{ Dominant } & $\mathrm{C} / \mathrm{C}(n=132)$ & $8.65(7.40-9.90)$ & 0.099 & 0.188 & 1.00 (ref.) & - & - \\
\hline & & $\mathrm{C} / \mathrm{T}+\mathrm{T} / \mathrm{T}(n=197)$ & $9.65(8.51-10.79)$ & & & $1.55(0.98-2.45)$ & 0.064 & 0.128 \\
\hline & \multirow[t]{2}{*}{ Recessive } & $\mathrm{C} / \mathrm{C}+\mathrm{C} / \mathrm{T}(n=277)$ & $9.14(8.09-10.19)$ & 0.336 & 0.336 & 1.00 (ref.) & - & - \\
\hline & & $\mathrm{T} / \mathrm{T}(n=52)$ & $9.95(8.17-11.73)$ & & & $1.15(0.61-2.19)$ & 0.661 & 0.661 \\
\hline & Additive & For each risk allele $(\mathrm{T})$ increase & Slope (SE) 0.70 (0.42) & 0.101 & 0.202 & $1.29(0.93-1.78)$ & 0.130 & 0.260 \\
\hline
\end{tabular}

\footnotetext{
${ }^{a}$ Pre-post differences between Hamilton Rating Scale for Depression 21 items (HRSD-21) scores measured at the end of SSRI treatment and at baseline (models were adjusted for HRSD-21 score at baseline, age, sex, educational level, SSRI type, and 5-HTTLPR genotype)

${ }^{\mathrm{b}}$ Ordinal logistic regressions to model the probability of SSRI treatment response (models were adjusted for age, sex, educational level, SSRI type and 5-HTTLPR genotype)

${ }^{\mathrm{b}}$ Estimated means along $95 \%$ confidence interval (95\% CI). To represent a mean reduction, the signs of these mean estimates were reverted

${ }^{\mathrm{c}} p$ Values adjusted following Hochberg's method; slope: regression: slope along with standard error (SE)
} 
Table 5 Estimated frequencies of haplotypes spanning 4.5-kb block at the Klotho gene locus in patients responders (R), poor-responders (PR), and nonresponders (NR) to the treatment with selective serotonin reuptake inhibitors

\begin{tabular}{|c|c|c|c|c|c|c|c|c|c|c|c|c|c|}
\hline & & \multicolumn{4}{|c|}{ R vs. PR } & \multicolumn{4}{|c|}{ R vs. NR } & \multicolumn{4}{|c|}{ PR vs. NR } \\
\hline & & $\mathrm{R}$ & PR & $\chi^{2}$ & $p$ & $\mathrm{R}$ & NR & $\chi^{2}$ & $p$ & PR & NR & $\chi^{2}$ & $p$ \\
\hline H1 & CTC & 0.426 & 0.367 & 1.84 & 0.1749 & 0.433 & 0.367 & 1.539 & 0.2148 & 0.424 & 0.417 & 0.014 & 0.9051 \\
\hline $\mathrm{H} 2$ & CTT & 0.330 & 0.295 & 0.726 & 0.3943 & 0.249 & 0.291 & 0.707 & 0.4005 & 0.256 & 0.333 & 1.959 & 0.1616 \\
\hline $\mathrm{H} 3$ & CGC & 0.128 & 0.136 & 0.072 & 0.7879 & 0.188 & 0.140 & 1.441 & 0.23 & 0.190 & 0.134 & 1.726 & 0.1889 \\
\hline H4 & TTT & 0.048 & 0.105 & 5.26 & 0.0218 & 0.056 & 0.110 & 2.695 & 0.1007 & 0.067 & 0.058 & 0.098 & 0.7543 \\
\hline H5 & TTC & 0.049 & 0.062 & 0.393 & 0.5307 & 0.058 & 0.062 & 0.03 & 0.8627 & 0.049 & 0.045 & 0.024 & 0.8765 \\
\hline H6 & TGC & 0.019 & 0.035 & 1.139 & 0.2858 & 0.016 & 0.030 & 0.629 & 0.4277 & 0.014 & 0.013 & 0.002 & 0.9658 \\
\hline
\end{tabular}

$>35 \%$, followed by $\mathrm{H} 2(>25 \%)$ and $\mathrm{H} 3(>10 \%)$. All the other haplotypes were represented with a frequency $<10 \%$. No important differences were observed when the study groups were compared with each other. Only a minor difference was observed in the comparison of R vs. PR patients, resulting in a significant overrepresentation of haplotype $\mathrm{H} 4$ in PR patients $(0.048$ vs. $0.105 ; p=0.022)$. A schematic representation of the LD coefficient $r^{2}$ is shown in Fig. 2. No important differences were observed when the study groups were compared with each other. Only a minor difference was observed in NR patients. In this group, an increased LD was observed between SNPs rs1207568 and rs9536314 $\left(r^{2}=0.038\right)$.

\section{Discussion}

The present study showed a significant association between mutation of SNP KL rs1207568 and a better response to SSRI treatment in patients with late-life MDD. Conversely, a significantly higher frequency of the minor genotype of SNP KL rs9536314 was found in NR patients to the antidepressant

Fig. 2 Schematic representation of $\mathrm{r}^{2}$ linkage disequilibrium coefficient at the $4.5-\mathrm{kb}$ block spanning the klotho gene (KL) locus treatment. We confirmed also a significant improvement of depressive symptoms after SSRI treatment in patients carrying at least one minor allele at KL rs1207568 and a worse response in patients homozygous for the minor allele at $\mathrm{KL}$ rs9536314. These results suggested a possible role of KL in the complex pathway of SSRI response in late-life MDD.

At the best of our knowledge, the present was the first study reporting an association between the KL locus and the response to SSRI treatment in late-life MDD. Indeed, there is little information to date regarding possible associations of gene polymorphisms with a clinical response to different SSRIs. Candidate genes for these association analyses included polymorphisms affecting the serotonin transporter, serotonin receptors, intracellular transduction, noradrenergic and other neurotransmitter systems, the hypothalamic-pituitary adrenal (HPA) axis, the brain-derived neurotrophic factor (BDNF), and related alteration in adult hippocampal neurogenesis [33-36, 53]. We selected the KL locus because Klotho protein is involved in the dysregulation of the stress system response related to depression $[20,26]$ and in the aging processes [25]. Furthermore, given that other genes may affect clinical aspects of late-life MDD, or may influence the clinical

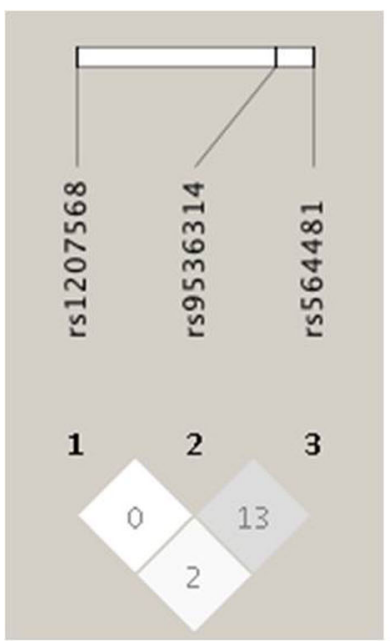

Poor responders

Non responders

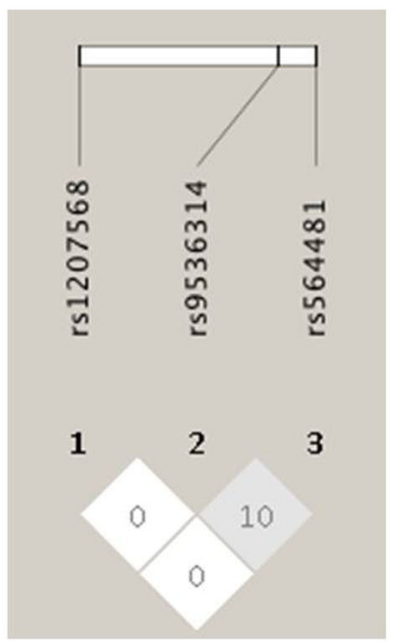

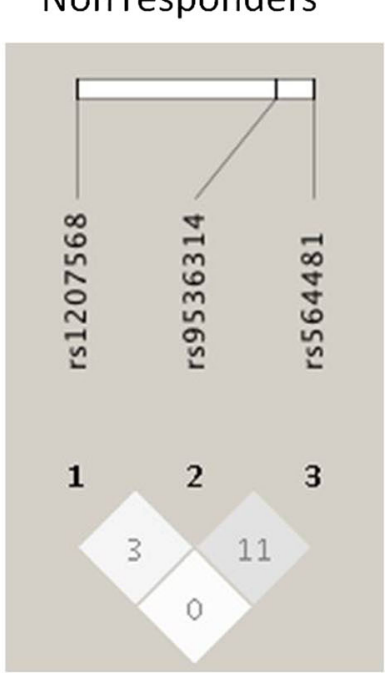


response to treatments $[48,54]$, we studied two genetic polymorphisms already known as possible interaction with SSRI response to treatment (i.e., the SLC6A4 5-HTTLPR and CYP2D6 SNPs). We choose these two SNPs since the first was probably the most cited polymorphism around the world [55], whereas the second is pivotal in SSRI metabolism (http:// www.drugbank.ca). However, other genes might influence the response of late-life MDD to antidepressant treatment (i.e., genes encoding guanine nucleotide binding protein beta polypeptide 3, 5-hydroxytryptamine receptor $2 \mathrm{~A}$, catechol Omethyltransferase, $51 \mathrm{kDa}$ immunophilin, and neuregulin-1 among others) [56-59]. The present analyses did not show any significant association with the SLC6A4 and CYP2D6 polymorphisms, suggesting that the effect of KL locus was not significantly influenced by other known genetic factors linked with clinical features of late-life MDD.

Some allele-specific molecular mechanisms may be hypothesized to help explain the present observed associations. In particular, a common haplotype, termed KL-VS, composed of six SNPs in perfect LD (including KL rs9536314) is present in $\sim 15 \%$ of Caucasians [46]. It has been suggested that this $\mathrm{KL}$ variant may influence the trafficking and the catalytic activity of Klotho protein [46], giving a survival advantage to KL-VS heterozygotes [46, 60], who have also higher serum Klotho levels [46, 61] and better cognitive functions [61, 62]. Very recently, lower levels of Klotho have been associated with high chronic stress and with depressive symptoms in young, otherwise healthy women [63], suggesting that Klotho may serve as a novel biological link connecting stress, depression, and risk for accelerated disease development. Therefore, some KL genetic variants, including KL rs9536314, may modulate serum Klotho levels and lower levels of circulating Klotho were further linked to high chronic stress and depressive symptoms partly explaining the possible role of KL locus in the response to antidepressant treatment.

Among other possible mechanisms linking the KL locus to the response to antidepressant treatment, it is well known that SSRIs can decrease synaptic function in selected areas by influencing calcium channels [45] and Klotho protein modulates central nervous system (CNS) calcium metabolism by mediation of the transport of calcium across the blood-brain barrier [64]. Indeed, Klotho is a type I transmembrane protein cleaved by ADAM 10 and ADAM17 from the cell membrane $[65,66]$, and the $139-\mathrm{kD}$ extracellular domain is detectable in serum and cerebrospinal fluid [67]. Its functions include regulation of fibroblast growth factor-23 (FGF23) signaling, suppression of the insulin/insulin-like growth factor-1 (IGF-1) and Wingless-type protein (Wnt) signaling pathways, and regulation of calcium and phosphate homeostasis [45, 68].

Moreover, in animal models the decrease of Klotho protein reduced synaptic density in the hippocampus as a reflection of increased oxidative stress [28]. Indeed, Klotho-deficient mice showed a pronounced deficiency of the nitric oxide system with resultant widespread endothelial pathology [69], with a generalized increase in the overall burden of oxidative stress in the CNS [27]. Therefore, Klotho may have brain antioxidative and anti-inflammatory effects [28, 29], improving the efficiency of two strictly interrelated systems, ER stress and parainflammation, potentially interfering with all phases of a normal stress response in depressive syndromes, including adaptive hippocampal neurogenesis [20], and the ability to generate neural stem cells [70].

Hippocampal neurogenesis can be considered a process underlying antidepressant response, related to the generation of new functional neurons [35, 71]. Growth factors such as the BDNF has been shown to enhance hippocampal neurogenesis [72]. IGF-1 may mediate the exercise-induced effects on BDNF, hippocampal neurogenesis, and cognitive performance [73], while growth factors, specifically FGF23 and IGF-1 receptors and/or their downstream signaling pathways may interact with the KL locus [45, 68]. Moreover, Klotho, peroxisome proliferator-activated receptor- $\gamma$ (PPAR- $\gamma)$ systems, and CNS insulin may have a role as potential modulators of stress processes in MDD [20]. Repeated social and other stressors plus genetic predisposition may lead to decreased neuronal resilience and depression. In particular, the PPAR- $\gamma$ system can modulate and diminish different pathological drivers of MDD, such as parainflammation [74], extreme ER stress responses [75], glutamate toxicity, oxidative stress, decreased neuroplasticity, and deficient neurogenesis [20]. Thus, Klotho should help to counteract stress-inducedparainflammation and ER stress limiting the deleterious effects of inflammatory and metabolic changes associated with MDD, and promoting an adaptive response to treatment [20].

We selected patients with late-life MDD and late onset of depression using tight diagnostic validated criteria, using also proportional odds models, which incorporate the ordinal nature of treatment response and makes the association with genotypes much more reliable. Indeed, instead of considering the probability to be a responder with respect to the probability to be a nonresponder only (without including PR), with this model, it is possible to consider the probability to be responder with respect to all responder status. Moreover, we excluded possible genetic bias that could influence the response to SSRIs treatment and we verified all possible confounders that could affect statistical analysis. However, we did not consider significant MMSE score differences at follow-up as a confounder because a long-term cumulative depressive symptom burden on cognitive decline has been already described [76] Notwithstanding these strengths, some limitations of the present study should be acknowledged. First of all, the present was a nonrandomized, naturalistic study and recruitment of patients was limited to a single center in Italy, and these methodological aspects may have influenced the results, affecting their generalizability to other populations. Furthermore, the present sample consisted of individuals with late-life MDD, 
but there was no control group with younger individuals with depressive syndromes. Given that depression even early in life can be conceptualized as accelerated aging and Klotho is involved in both age-related changes [25] and the stress response more generally $[20,26]$, the present results may not be specific to LLD. Moreover, we could not separately analyze the response to different SSRIs, even if multivariable models adjusted for the different drugs have been used. Furthermore, the lack of intermediate assessment excluded those patients who have a different initial response or treatment-related adverse event. To avoid possible confounders, we used multivariable regression analysis adjusted for the baseline characteristics possibly influencing the response to antidepressant treatment. Notably, all these latelife MDD patients were classified as having a "true" drug response at six month, i.e., a response characterized by a clinical improvement not subsequently followed by a worsening of response (sustained clinical response) [77]. This may be a limitation of this study, since a time-course of symptoms during treatment was missing as well as the possibility to investigate the effects of KL polymorphisms on early/later response to SSRI treatment. Finally, given that KL locus, particularly the KL-VS, has been linked to cognition [61, 62], it is possible an association between the KL SNPs and depressive symptoms more closely tied to cognitive complaints (i.e., the item 8 "retardation" of HRSD-21 or the item 10 of GDS-15: "Do you feel you have more problems with your memory than most?"). Unfortunately, we did not include in the present dataset the score of the single items of HRSD-21 or GDS- 15 .

\section{Conclusion}

Given the present findings in late-life MDD, we could speculate that the Tallele of KL rs1207568 may be a factor inducing a better response to SSRI treatment, while the G allele of KL rs9536314 seemed to be a factor inhibiting the response to antidepressant treatment. Since a number of neurotransmitter and neuromodulatory systems are associated both with LLD and particularly late-life MDD and response to antidepressant treatment, each of these systems may offer a biologically plausible target for selection of candidate genes affecting SSRI response. This appears to be the case also for the KL locus. Empirically, the identification in these various systems of genetic polymorphisms influencing SSRI response could be an important goal for the next generation of studies examining treatment outcome in LLD. Further studies on larger population with different ages will be needed to clarify the clinical and biological role of KL polymorphisms in the response to SSRI treatment. However, because single polymorphisms are likely to have small effect sizes, identifying multiple genes may be mandatory to generate a complete picture of genetic variability and response to SSRI treatment.
Acknowledgments This work was fully supported by "Ministero della Salute", IRCCS Research Program, Ricerca Corrente 2012-2014, Linea n. 2 "Malattie complesse" and by the " $5 \times 1000$ " voluntary contribution.

\section{Compliance with Ethical Standards}

Conflict of Interest All authors reported no biomedical financial interests or potential conflicts of interest.

\section{References}

1. Naismith SL, Norrie LM, Mowszowski L, Hickie IB (2012) The neurobiology of depression in later-life: clinical, neuropsychological, neuroimaging and pathophysiological features. Prog Neurobiol 98:99-143

2. American Psychiatric Association (2000) Diagnostic and Statistical Manual of Mental Disorders. Fourth Edition, Text Revision (DSMIV-TR). American Psychiatric Publishing, Washington, DC.

3. Alexopoulos GS (2005) Depression in the elderly. Lancet 365: 1961-1970

4. Panza F, Frisardi V, Capurso C, D'Introno A, Colacicco AM, Imbimbo BP, Santamato A, Vendemiale G, Seripa D, Pilotto A, Capurso A, Solfrizzi V (2010) Late-life depression, mild cognitive impairment, and dementia: possible continuum? Am J Geriatr Psych 18:98-116

5. Luppa M, Sikorski C, Luck T, Ehreke L, Konnopka A, Wiese B, Weyerer S, König HH, Riedel-Heller SG (2012) Age- and genderspecific prevalence of depression in latest-life - systematic review and meta-analysis. J Affect Disord 136:212-221

6. Büchtemann D, Luppa M, Bramesfeld A, Riedel-Heller S (2012) Incidence of late-life depression: a systematic review. J Affect Disord 142:172-179

7. Gleason OC, Pierce AM, Walker AE, Warnock JK (2013) The twoway relationship between medical illness and late-life depression. Psychiatr Clin North Am 36:533-544

8. Pollock BG (2005) The pharmacokinetic imperative in late-life depression. J Clin Psychopharmacol 25(4 Suppl 1):S19-S23

9. Mezuk B, Lohman M, Dumenci L, Lapane KL (2013) Are depression and frailty overlapping syndromes in mid- and late-life? A latent variable analysis. Am J Geriatr Psychiatry 21:560-569

10. Pilotto A, D’Onofrio G, Panza F, Copetti M, Cascavilla L, Paris F, Pellegrini F, Seripa D, Ferrucci L (2012) Treatment of late-life major depressive disorder with selective serotonin reuptake inhibitors improves the multidimensional prognostic index. J Clin Psychopharmacol 32:726-729

11. World Economic Forum (2011) Global burden of mental disorders and the need for a comprehensive, coordinated response from health and social sectors at the country level. World Health Organization; EXECUTIVE BOARD EB130/9. http://apps.who.int/gb/ebwha/ pdf_files/EB130/B130_9-en.pdf

12. Ellison JM, Kyomen HH, Harper DG (2012) Depression in later life: an overview with treatment recommendations. Psychiatr Clin North Am 35:203-229

13. Rojas-Fernandez CH, Miller LJ, Sadowski CA (2010) Considerations in the treatment of geriatric depression: overview of pharmacotherapeutic and psychotherapeutic treatment interventions. Res Gerontol Nurs 3:176-186

14. Gold PW, Goodwin FK, Chrousos GP (1988) Clinical and biochemical manifestations of depression. Relation to the neurobiology of stress (a). N Engl J Med 319:348-353

15. Gold PW, Goodwin FK, Chrousos GP (1988) Clinical and biochemical manifestations of depression. Relation to the neurobiology of stress (b). N Engl J Med 319:1428 
16. Sun MK, Alkon DL (2014) Stress: perspectives on its impact on cognition and pharmacological treatment. Behav Pharmacol 25(56): $410-424$

17. Medzhitov R (2008) Origin and physiological roles of inflammation. Nature 454:428-435

18. Hotamisligil GS (2010) Endoplasmic reticulum stress and the inflammatory basis of metabolic disease. Cell 140:900-917

19. Zhang X, Zhang G, Zhang H, Karin M, Bai H, Cai D (2008) Hypothalamic IKKbeta/NFkappaB and ER stress link overnutrition to energy imbalance and obesity. Cell 135:61-73

20. Gold PW, Licinio J, Pavlatou MG (2013) Pathological parainflammation and endoplasmic reticulum stress in depression: potential translational targets through the CNS insulin, klotho and PPAR- $\gamma$ systems. Mol Psychiatry 18:154-165

21. Kim I, Xu W, Reed J (2008) Cell death and endoplasmic reticulum stress: disease relevance and therapeutic opportunities. Nat Rev Drug Discov 7:1013-1030

22. Lin JH, Walter P, Yen TS (2008) Endoplasmic reticulum stress in disease pathogenesis. Annu Rev Pathol 3:399-425

23. Ozcan U, Cao Q, Yilmaz E, Lee AH, Iwakoshi NN, Ozdelen E, Tuncman G, Görgün C, Glimcher LH, Hotamisligil GS (2004) Endoplasmic reticulum stress links obesity, insulin action, and type 2 diabetes. Science 306:457-461

24. Zhao L, Ackerman SL (2006) Endoplasmic reticulum stress in health and disease. Curr Opin Cell Biol 18:444-452

25. Kuro-o M, Matsumura Y, Aizawa H, Kawaguchi H, Suga T, Utsugi T, Ohyama Y, Kurabayashi M, Kaname T, Kume E, Iwasaki H, Iida A, Shiraki-Iida T, Nishikawa S, Nagai R, Nabeshima YI (1997) Mutation of the mouse klotho gene leads to a syndrome resembling ageing. Nature 390:45-51

26. Banerjee S, Zhao Y, Sarkar PS, Rosenblatt KP, Tilton RG, Choudhary S (2013) Klotho ameliorates chemically induced endoplasmic reticulum (ER) stress signaling. Cell Physiol Biochem 31: 659-672

27. Kurosu H, Yamamoto M, Clark JD, Pastor JV, Nandi A, Gurnani P, McGuinness OP, Chikuda H, Yamaguchi M, Kawaguchi H, Shimomura I, Takayama Y, Herz J, Kahn CR, Rosenblatt KP, Kuro-o M (2005) Suppression of aging in mice by the hormone Klotho. Science 309:1829-1833

28. Kuro-o M (2008) Klotho as a regulator of oxidative stress and senescence. Biol Chem 389:233-241

29. Nagai T, Yamada K, Kim HC, Kim YS, Noda Y, Imura A, Nabeshima Y, Nabeshima T (2003) Cognition impairment in the genetic model of aging klotho gene mutant mice: a role of oxidative stress. FASEB J 17:50-52

30. Unützer J (2007) Clinical practice. Late-life depression. N Engl J Med 357:2269-2275

31. 26. NIH Consensus Conference (1992) Diagnosis and treatment of depression in late life. JAMA 268:1018-1024

32. Gottfries CG (2001) Late life depression. Eur Arch Psychiatry Clin Neurosci 251(Suppl2):57-61

33. Abo R, Hebbring S, Ji Y, Zhu H, Zeng ZB, Batzler A, Jenkins GD, Biernacka J, Snyder K, Drews M, Fiehn O, Fridley B, Schaid D, Kamatani N, Nakamura Y, Kubo M, Mushiroda T, KaddurahDaouk R, Mrazek DA, Weinshilboum RM (2012) Merging pharmacometabolomics with pharmacogenomics using ' 1000 Genomes' single-nucleotide polymorphism imputation: selective serotonin reuptake inhibitor response pharmacogenomics. Pharmacogenet Genomics 22:247-253

34. Kroeze Y, Zhou H, Homberg JR (2012) The genetics of selective serotonin reuptake inhibitors. Pharmacol Ther 136:375-400

35. El-Hage W, Leman S, Camus V, Belzung C (2013) Mechanisms of antidepressant resistance. Front Pharmacol 4:146

36. Pitychoutis PM, Kokras N, Sanoudou D, Dalla C, PapadopoulouDaifoti Z (2013) Pharmacogenetic considerations for late life depression therapy. Expert Opin Drug Metab Toxicol 9:989-999
37. von Elm E, Altman DG, Egger M, Pocock SJ, Gøtzsche PC, Vandenbroucke JP, STROBE Initiative (2007) Strengthening the Reporting of Observational Studies in Epidemiology (STROBE) statement: guidelines for reporting observational studies. BMJ 335:806-808

38. Folstein M, Folstein S, McHugh PR (1975) Mini-Mental State: a practical method for grading the cognitive state of patients for the clinician. J Psychiatr Res 12:189-198

39. Yesavage JA, Brink TL, Rose TL, Lum O, Huang V, Adey M, Leirer VO (1982-1983) Development and validation of a geriatric depression screening scale: a preliminary report. J Psychiatr Res 17: $37-49$

40. D'Ath P, Katona P, Mullan E, Evans S, Katona C (1994) Screening, detection and management of depression in elderly primary care attenders. I: the acceptability and performance of the 15 item Geriatric Depression Scale (GDS-15) and the development of short versions. Fam Pract 11:260-266

41. McGivney SA, Mulvihill M, Taylor B (1994) Validating the GDS depression screen in the nursing home. J Am Geriatr Soc 42:490-492

42. Hamilton M (1960) A rating scale for depression. J Neurol Neurosurg Psychiatry 23:56-62

43. Alexopoulos GS, Canuso CM, Gharabawi GM, Bossie CA, Greenspan A, Turkoz I, Reynolds C (2008) Placebocontrolled study of relapse prevention with risperidone augmentation in older patients with resistant depression. Am J Geriatr Psychiatry 16:21-30

44. Miller SA, Dykes DD, Polesky HF (1988) A simple salting out procedure for extracting DNA from human nucleated cells. Nucleic Acids Res 16:1215

45. Wang Y, Sun Z (2009) Current understanding of klotho. Ageing Res Rev 8:43-51

46. Arking DE, Krebsova A, Macek M Sr, Macek M Jr, Arking A, Mian IS, Fried L, Hamosh A, Dey S, McIntosh I, Dietz HC (2002) Association of human aging with a functional variant of klotho. Proc Natl Acad Sci U S A 99:856-861

47. Seripa D, Panza F, D’Onofrio G, Paroni G, Bizzarro A, Fontana A, Paris F, Cascavilla L, Copetti M, Masullo C, Pilotto A (2013) The serotonin transporter gene locus in late-life major depressive disorder. Am J Geriatr Psychiatry 21:67-77

48. Seripa D, Bizzarro A, Pilotto A, D’Onofrio G, Vecchione G, Gallo AP, Cascavilla L, Paris F, Grandone E, Mecocci P, Santini SA, Masullo C, Pilotto A (2011) Role of cytochrome P4502D6 functional polymorphisms in the efficacy of donepezil in patients with Alzheimer's disease. Pharmacogenet Genomics $21: 225-230$

49. Lewis CM (2002) Genetic association studies: design, analysis and interpretation. Brief Bioinform 3:146-153

50. Minelli C, Thompson JR, Abrams KR, Thakkinstian A, Attia $\mathrm{J}$ (2005) The choice of a genetic model in the meta-analysis of molecular association studies. Int J Epidemiol 34:13191328

51. Barret JC, Fry B, Maller J, Daly MJ (2005) Haploview: Analysis and visualization of LD and haplotype maps. Bioinformatics 21: 263-265

52. Cohen J (1992) A power primer. Psychol Bull 112:155-159

53. Sathyanesan M, Girgenti MJ, Banasr M, Stone K, Bruce C, Guilchicek E, Wilczak-Havill K, Nairn A, Williams K, Sass S, Duman JG, Newton SS (2012) A molecular characterization of the choroid plexus and stress-induced gene regulation. Transl Psychiatry 2:e139

54. Vaswani M, Linda FK, Ramesh S (2003) Role of selective serotonin reuptake inhibitors in psychiatric disorders: a comprehensive review. Prog Neuropsychopharmacol Biol Psychiatry 27:85-102 
55. Iurescia S, Seripa D, Rinaldi M (2015) Role of the 5-HTTLPR and SNP Promoter Polymorphisms on Serotonin Transporter Gene Expression: a Closer Look at Genetic Architecture and In Vitro Functional Studies of Common and Uncommon Allelic Variants. Mol Neurobiol [Epub ahead of print] doi:10.1007/s12035-015-9409-6.

56. Lin E1, Chen PS, Chang HH, Gean PW, Tsai HC, Yang YK, Lu RB (2009) Interaction of serotonin-related genes affects short-term antidepressant response in major depressive disorder. Prog Neuropsychopharmacol Biol Psychiatry 33:1167-1172

57. Ji Y, Biernacka J, Snyder K, Drews M, Pelleymounter LL, Colby C, Wang L, Mrazek DA, Weinshilboum RM (2012) Catechol Omethyltransferase pharmacogenomics and selective serotonin reuptake inhibitor response. Pharmacogenomics J 12:78-85

58. Ellsworth KA1, Moon I, Eckloff BW, Fridley BL, Jenkins GD, Batzler A, Biernacka JM, Abo R, Brisbin A, Ji Y, Hebbring S, Wieben ED, Mrazek DA, Weinshilboum RM, Wang L (2013) FKBP5 genetic variation: association with selective serotonin reuptake inhibitor treatment outcomes in major depressive disorder. Pharmacogenet Genomics 23:156-166

59. Biernacka JM, Sangkuhl K, Jenkins G, Whaley RM, Barman P, Batzler A, Altman RB, Arolt V, Brockmöller J, Chen CH, Domschke K, Hall-Flavin DK, Hong CJ, Illi A, Ji Y, Kampman O, Kinoshita T, Leinonen E, Liou YJ, Mushiroda T, Nonen S, Skime MK, Wang L, Baune BT, Kato M, Liu YL, Praphanphoj V, Stingl JC, Tsai SJ, Kubo M, Klein TE, Weinshilboum R (2015) The International SSRI Pharmacogenomics Consortium (ISPC): a genome-wide association study of antidepressant treatment response. Transl Psychiatry 5:e553

60. Arking DE, Atzmon G, Arking A, Barzilai N, Dietz HC (2005) Association between a functional variant of the KLOTHO gene and high-density lipoprotein cholesterol, blood pressure, stroke, and longevity. Circ Res 96:412-418

61. Dubal DB, Yokoyama JS, Zhu L, Broestl L, Worden K, Wang D, Sturm VE, Kim D, Klein E, Yu GQ, Ho K, Eilertson KE, Yu L, Kuro-o M, De Jager PL, Coppola G, Small GW, Bennett DA, Kramer JH, Abraham CR, Miller BL, Mucke L (2014) Life extension factor klotho enhances cognition. Cell Rep 7:1065-1076

62. Yokoyama JS, Sturm VE, Bonham LW, Klein E, Arfanakis K, Yu L, Coppola G, Kramer JH, Bennett DA, Miller BL, Dubal DB (2015) Variation in longevity gene KLOTHO is associated with greater cortical volumes. Ann Clin Transl Neurol 2:215-230

63. Prather AA, Epel ES, Arenander J, Broestl L, Garay BI, Wang D, Dubal DB (2015) Longevity factor klotho and chronic psychological stress. Transl Psychiatry $5: \mathrm{e} 585$

64. Imura A, Tsuji Y, Murata M, Maeda R, Kubota K, Iwano A, Obuse C, Togashi K, Tominaga M, Kita N, Tomiyama K, Iijima J, Nabeshima Y, Fujioka M, Asato R, Tanaka S, Kojima K, Ito J, Nozaki K, Hashimoto N, Ito T, Nishio T, Uchiyama T, Fujimori T, Nabeshima Y (2007) alpha-Klotho as a regulator of calcium homeostasis. Science 316:1615-1618

65. Chen CD, Podvin S, Gillespie E, Leeman SE, Abraham CR (2007) Insulin stimulates the cleavage and release of the extracellular domain of Klotho by ADAM10 and ADAM17. Proc Natl Acad Sci U S A 104:19796-19801

66. Bloch L, Sineshchekova O, Reichenbach D, Reiss K, Saftig P, Kuro-o M (2009) Klotho is a substrate for $\alpha$-, $\beta$ - and $\gamma$-secretase. FEBS Lett 583:3221-3224

67. Imura A, Iwano A, Tohyama O, Tsuji Y, Nozaki K, Hashimoto N (2004) Secreted Klotho protein in sera and CSF: implication for post-translational cleavage in release of Klotho protein from cell membrane. FEBS Lett 565:143-147

68. Kuro-o M (2010) A potential link between phosphate and aging-lessons from Klotho-deficient mice. Mech Ageing Dev 131:270-275

69. Saito Y, Yamagishi T, Nakamura T, Ohyama Y, Aizawa H, Suga T, Matsumura Y, Masuda H, Kurabayashi M, Kuro-o M, Nabeshima Y, Nagai R (1998) Klotho protein protects against endothelial dysfunction. Biochem Biophys Res Commun 248:324-329

70. Li SA, Watanabe M, Yamada H, Nagai A, Kinuta M, Takei K (2004) Immunohistochemical localization of Klotho protein in brain, kidney, and reproductive organs of mice. Cell Struct Funct 29:91-99

71. Santarelli L, Saxe M, Gross C, Surget A, Battaglia F, Dulawa S, Weisstaub N, Lee J, Duman R, Arancio O, Belzung C, Hen R (2003) Requirement of hippocampal neurogenesis for the behavioral effects of antidepressants. Science 301:805-809

72. Erickson KI, Prakash RS, Voss MW, Chaddock L, Heo S, McLaren M, Pence BD, Martin SA, Vieira VJ, Woods JA, McAuley E, Kramer AF (2010) Brain-derived neurotrophic factor is associated with age-related decline in hippocampal volume. J Neurosci 30: 5368-5375

73. Trejo JL, Carro E, Torres-Aleman I (2001) Circulating insulinlike growth factor I mediates exercise-induced increases in the number of new neurons in the adult hippocampus. J Neurosci 21:1628-1634

74. Yi JH, Park SW, Kapadia R, Vemuganti R (2007) Role of transcription factors in mediating post-ischemic cerebral inflammation and brain damage. Neurochem Int 50:1014-1027

75. Evans-Molina C, Robbins RD, Kono T, Tersey SA, Vestermark GL, Nunemaker CS, Garmey JC, Deering TG, Keller SR, Maier B, Mirmira RG (2009) Peroxisome proliferator-activated receptor gamma activation restores islet function in diabetic mice through reduction of endoplasmic reticulum stress and maintenance of euchromatin structure. Mol Cell Biol 29:2053-2067

76. Zeki Al Hazzouri A, Vittinghoff E, Byers A, Covinsky K, Blazer D, Diem S, Ensrud KE, Yaffe K (2014) Long-term cumulative depressive symptom burden and risk of cognitive decline and dementia among very old women. J Gerontol A Biol Sci Med Sci 69:595-601

77. Papakostas GI, Perlis RH, Scalia MJ, Petersen TJ, Fava M (2006) A meta-analysis of early sustained response rates between antidepressants and placebo for the treatment of major depressive disorder. J Clin Psychopharmacol 26:56-60 